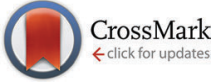

Cite this: Chem. Commun., 2016, 52,7368

Received 1st February 2016, Accepted 19th February 2016

DOI: $10.1039 / \mathrm{c} 6 \mathrm{cc} 01032 f$

www.rsc.org/chemcomm

\section{Controlled production of the elusive metastable form II of acetaminophen (paracetamol): a fully scalable templating approach in a cooling environment $\dagger$}

\author{
Lauren R. Agnew, ${ }^{\text {ab }}$ Dyanne L. Cruickshank, ${ }^{c}$ Thomas McGlone ${ }^{d}$ and \\ Chick C. Wilson*ab
}

\begin{abstract}
A scalable, transferable, cooling crystallisation route to the elusive, metastable, form II of the API acetaminophen (paracetamol) has been developed using a multicomponent "templating" approach, delivering $100 \%$ polymorphic phase pure form II at scales up to $120 \mathrm{~g}$. Favourable solubility and stability properties are found for the form II samples.
\end{abstract}

Enhancing physiochemical properties of active pharmaceutical ingredients (APIs) has been widely researched in recent years to aid in the downstream processing of many pharmaceuticals. For example, increased aqueous solubility results in higher bioavailability, the ability to engineer layered structures can result in improved compaction properties, and modifying the stability of APIs can be of critical importance in transportation and storage. Such property enhancement can be achieved both in polymorphic forms of the API, and in multicomponent molecular complexes containing the API (e.g. co-crystals). There have been numerous reports on the use of multicomponent crystallisation procedures, in particular co-crystallisation, to achieve such physical property enhancement. ${ }^{1-5}$ However, there are very limited reports targeting different polymorphic forms of single component APIs using a multicomponent approach. A range of API molecules have been shown to be polymorphic on crystallisation into the solid state; containing only the desired API, these polymorphs can display markedly different physical properties. Many of these polymorphic forms can be elusive and accessible under specialised conditions or in low yields,

\footnotetext{
${ }^{a}$ EPSRC Centre for Innovative Manufacturing in Continuous Manufacturing and Crystallisation, University of Bath, Bath, BA2 7AY, UK.

E-mail: C.C.Wilson@bath.ac.uk

${ }^{b}$ Department of Chemistry, University of Bath, Bath, BA2 7AY, UK

${ }^{c}$ Department of Chemistry, University of Cape Town, Rondebosch, 7701, South Africa

${ }^{d}$ EPSRC Centre for Innovative Manufacturing in Continuous Manufacturing and Crystallisation, c/o Strathclyde Institute for Pharmacy and Biomedical Sciences, Technology and Innovation Centre, 99 George Street, Glasgow, G1 1RD, UK $\dagger$ Electronic supplementary information (ESI) available: Solubility curves, PXRD and DSC patterns. See DOI: 10.1039/c6cc01032f
}

which hampers the potential to manufacture and utilise them in pharmaceutical products. Of relevance to the work presented here, a number of elusive, metastable polymorphic forms have been discovered serendipitously through attempted co-crystallisation experiments. ${ }^{6-8}$ Systems such as these have introduced the idea of using a second molecular component, termed here a templating molecule, in the crystallisation process to isolate and convert a previously stable polymorphic form of the target API to a new and often elusive metastable form, while not being present itself in the final product. Crucially, this has previously rarely been achieved by design and in this work such a designed process is not only achieved, but scaled to produce large quantities of an elusive polymorph with enhanced physical properties.

Acetaminophen (paracetamol; PCM) is a widely used analgesic and antipyretic which has been studied extensively in the solid state. ${ }^{9-12}$ It exists in five polymorphic forms (of which two can only be accessed at high pressure), two of which have relevance in this work (Fig. 1). Form I displays a herringbone arrangement of molecules within the crystal structure, whilst form II is layered. This layering gives form II the enhanced physical properties of increased solubility (assisting bioavailability) and compressibility upon tableting (assisting processing). Previous routes to obtaining metastable form II include reaction coupling, ${ }^{13}$ swift cooling, ${ }^{14}$ enforcing Ostwald's rule of stages, ${ }^{15}$ use of polymer additives, ${ }^{16}$ heterogeneous nucleation ${ }^{17}$ and multicomponent templating approaches. ${ }^{18}$ The last of these has shown the possibility to template form II with a variety of benzoic acid (BA) derivatives. However, this was only achieved in an evaporative crystallisation environment. ${ }^{18}$

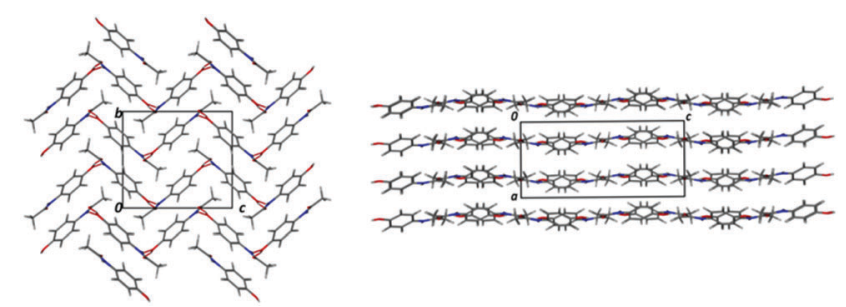

Fig. 1 PCM-I (left) and PCM-II (right). 
The present work looks at the production of metastable form II, with 4-halobenzoic acid derivatives (4-bromobenzoic acid (4-BrBA), 4-chlorobenzoic acid (4-ClBA), 4-fluorobenzoic acid (4-FBA)) as templating molecules, in a cooling crystallisation environment. The 4-substituted benzoic acid derivatives were shown to produce form II most reliably in evaporative studies and so were chosen as initial additives. Here, we develop this designed approach by also using the structurally similar molecule metacetamol (MCM), only previously studied in relation to its effect on PCM-I morphology, ${ }^{19,20}$ as a templating molecule for PCM-II production. Use of this designed templating approach to access a range of elusive solid forms in a "discovery" context has also recently been discussed by Thomas et al. in a complementary paper in this issue.

Cooling crystallisation is becoming more widely used in industry, as it offers improved control of the supersaturation within the system and hence greater control of both polymorphic form and particle attributes, with many continuous manufacturing processes, such as those using the continuous oscillatory baffled crystalliser ${ }^{21}$ and mixed suspension mixed product removal platforms, ${ }^{22}$ employing it. There are a number of examples in the literature using cooling crystallisation methods with single component systems but to date obtaining polymorphic control of a single-molecule API system in a cooling environment with more than one (non-solvent) molecular component present has not been achieved. With regard to the PCM system, previous cooling crystallisation experiments, have shown the reproducible formation of only PCM-I. ${ }^{23}$ A solution-mediated phase transition from form II to form I does, however, occur during cooling, consistent with Ostwald's rule of stages.

In this work, the Polar Bear Plus Crystalliser from Cambridge Reactor Design is used to provide controlled cooling crystallisation conditions, in a systematic study of the production of PCM-II using a templating approach. $1.5 \mathrm{~cm}^{3}$ vials containing ca. $250 \mathrm{mg}$ of paracetamol, varying weight percentages of BA templating molecules $(0.4-2 \%$ for 4 -BrBA and 4 -ClBA and $1-4 \%$ for 4-FBA) and $1 \mathrm{~g}$ of $60: 40 \mathrm{v} / \mathrm{v} \mathrm{H}_{2} \mathrm{O}$ : IPA solvent were subjected to a stepped cooling profile (Fig. 2) from 70 to $5{ }^{\circ} \mathrm{C}$ at a rate of $0.02{ }^{\circ} \mathrm{C} \mathrm{min}{ }^{-1}$. Solutions were cooled in $5{ }^{\circ} \mathrm{C}$ intervals and subsequently stirred for one hour to reach steady state conditions. Magnetic bottom stirring was used at a rate of either $800 \mathrm{rpm}$ or $400 \mathrm{rpm}$. The experiments were designed to ensure that the BA templating molecule remained in solution at the end of the crystallisation (informed by solubility curves, ESI, $\dagger$ Fig. S1). A variety of cooling rates were investigated in order to optimise the crystallisation process, however production of PCM-II with BA co-former templating molecules was only achieved using the cooling conditions described above.

For MCM, varying weight percentages $(1,2,5,10$ and $25 \%)$ as a proportion of $c a .250 \mathrm{mg}$ PCM and $1 \mathrm{~g}$ of one of three solvents (ethanol, IPA or 60:40 $\mathrm{H}_{2} \mathrm{O}$ :IPA) were subjected to both a stepped cooling profile (Fig. 2) at three different cooling rates: $0.02{ }^{\circ} \mathrm{C} \mathrm{min}{ }^{-1}, 0.2{ }^{\circ} \mathrm{C} \mathrm{min}^{-1}$ and $1{ }^{\circ} \mathrm{C} \min ^{-1}$ and a linear cooling profile at $1{ }^{\circ} \mathrm{C} \mathrm{min}^{-1}$; the latter, rapid cooling rate, was used to mimic the cooling conditions that may be more relevant to continuous crystallisation. Larger vials $(20 \mathrm{ml})$ and

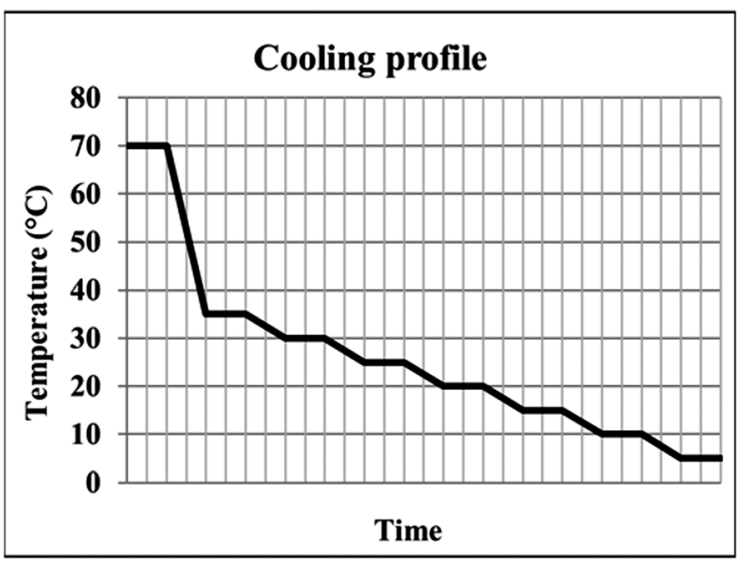

Fig. 2 The stepped cooling profile employed, showing the six regions of dwelling employed to ensure steady state is reached.

varying sizes of round bottomed flasks (RBFs) were used to scale up the production of PCM-II in the presence of MCM once the optimal cooling conditions had been established.

Powder X-ray diffraction (PXRD) confirms the formation of PCM-II (ESI, $\dagger$ Fig. S2), with no additional peaks corresponding to the presence of co-former, PCM-I or any other solid form. Differential scanning calorimetry (DSC) measurements confirmed the absence of any templating molecule in lower concentrations than detectable by PXRD or Raman spectroscopy (ESI, $\dagger$ Fig. S3).

Table 1 highlights the specific conditions used to obtain PCM-II in a designed, reproducible manner. The production of PCM-II is highly dependent on crystallisation conditions as well as the concentrations of both the co-former molecules and PCM; more recently, design of experiments analysis on the PCM/MCM system has allowed these effects to be quantified, enhancing the design element of this study. The concentrations of the co-former with respect to the solvents were chosen so that the templating molecule was undersaturated at $5{ }^{\circ} \mathrm{C}$, ensuring it remains in solution at the completion of the cooling regime. The higher stirring rates required for 4-BrBA can be attributed to the fact that these conditions provide the greater mass transfer required for lower concentrations of 4-BrBA. Investigations into the scaling potential of the templated crystallisation of PCM-II with 4-FBA have been largely unsuccessful. It can be suggested that this is due to poor mass transfer at higher scales and the low solubility of the co-former molecule.

On the other hand, the use of MCM as a templating molecule has allowed for the reproducible scale-up to the $10 \mathrm{ml}$ solvent scale ( $c a .2 .5 \mathrm{~g}$ PCM) at all three cooling rates and all cooling profiles currently explored. Scaled production of PCM-II using a rapid cooling rate of $1{ }^{\circ} \mathrm{C} \mathrm{min}{ }^{-1}$ is a significant step towards mimicking the conditions that would likely be experienced in operational continuous crystallisation platforms. Further scale-up attempts required increasing the concentration of MCM and truncating the cooling at a final temperature of $20^{\circ} \mathrm{C}$, allowing the system to be scaled into a $50 \mathrm{ml}$ RBF, yielding large quantities of $>10 \mathrm{~g}$ of $100 \%$ pure PCM-II in single runs. It can be suggested that the higher concentrations of MCM are needed to account for the poorer mass transfer experienced through magnetic bottom 
Table 1 Specific conditions under which production of PCM form II has been achieved reproducibly

\begin{tabular}{|c|c|c|c|c|c|c|}
\hline Stirring rate $(\mathrm{rpm})$ & Co-former & Solvent & 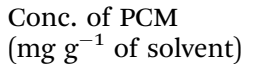 & $\begin{array}{l}\text { Cooling rate } \\
\left({ }^{\circ} \mathrm{C} \mathrm{m^{-1 } )}\right.\end{array}$ & $\begin{array}{l}\text { Cooling } \\
\text { profile }\end{array}$ & $\mathrm{wt} \%$ co-former \\
\hline 800 & 4-BrBA & $60: 40 \mathrm{H}_{2} \mathrm{O}:$ IPA & 250 & 0.02 & Stepped & $0.4,1.6,2$ \\
\hline 400 & 4-FBA & $60: 40 \mathrm{H}_{2} \mathrm{O}:$ IPA & 260 & 0.02 & Stepped & 3.5 \\
\hline 400 & Metacetamol & EtOH & 250 & 0.02 & Stepped & $5,10,25^{a}$ \\
\hline 400 & Metacetamol & $60: 40 \mathrm{H}_{2} \mathrm{O}:$ IPA & 250 & 0.2 & Stepped & 10,15 \\
\hline 400 & Metacetamol & EtOH & 250 & 0.2 & Stepped & $5,10,15$ \\
\hline 400 & Metacetamol & $60: 40 \mathrm{H}_{2} \mathrm{O}:$ IPA & 250 & 1 & Linear & $10,20,25^{a}$ \\
\hline 400 & Metacetamol & EtOH & 250 & 1 & Linear & $10,20,25^{a}$ \\
\hline
\end{tabular}

${ }^{a}$ Vials containing higher concentrations of metacetamol contained some metacetamol in the solid product. This was mitigated by cooling to higher temperatures.

stirring at larger scales. Use of overhead stirring, and the greater associated mass transfer, has allowed for the further scaling of the system to volumes as high as $800 \mathrm{ml}$, with production on the $100 \mathrm{ml}$ scale fully reproducible. Due to the widening of the metastable zone width with overhead stirring, a greater concentration of PCM was used; a concentration of $300 \mathrm{mg} \mathrm{g}^{-1}$ PCM coupled with $25 \mathrm{wt} \%$ MCM reproducibly gives $100 \%$ PCM-II. Currently, all samples of PCM-II produced are stable for periods of months (ESI, $\dagger$ Fig. S4), further confirming the absence of any form I, the presence of which would seed the conversion of form II back to the stable form I. The kinetics of this conversion are currently under investigation, with initial results showing that presence of $5 \mathrm{wt} \%$ or greater of form I in proportion to form II results in partial transformation, in the solid state, of the sample back to form I within a week. The stability of form II established here is significantly enhanced from that resulting from previously reported methods of obtaining PCM-II; the use of polymer additives gave samples that were only stable for five hours. ${ }^{16}$

It is worth noting that previous evaporative work emphasised the need to use stoichiometric ratios of PCM to co-former molecule to ensure the production of form II; the lower, at times catalytic, amounts used in this work under cooling conditions are in stark contrast to this.

A solubility curve for PCM-II has been previously reported, ${ }^{14}$ however the methodology or literature used to obtain these data were undisclosed. The aqueous solubility of PCM-II as determined using turbidimetric methods in a Technobis Crystal 16 device is thus reported here (Fig. 3; and in ESI $\dagger$ ), confirming and quantifying its enhanced solubility.

In summary, a multicomponent templating approach to paracetamol form II has been established in a cooling crystallisation environment using two templating molecules. Form II is produced reliably and in $100 \%$ polymorphic purity, with a $0.4-4 \%$ and $10-40 \% \mathrm{w} / \mathrm{w}$ co-former to PCM concentration for 4-fluorobenzoic acid and metacetamol respectively required to template this conversion. Metacetamol displays a higher solubility in the chosen solvent system than 4-fluorobenzoic acid and so higher concentrations were able to be used, aiding in the scale-up of the system to $800 \mathrm{ml}$ volume, producing $>100 \mathrm{~g}$ PCM-II in a single run. The crystallisation experiment was designed to ensure the templating co-former remains in solution

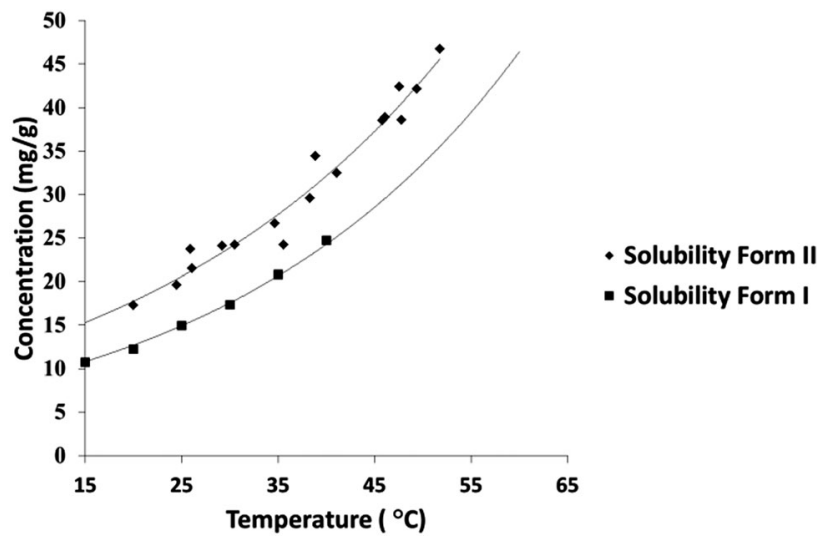

Fig. 3 Solubility curve showing the aqueous solubility of PCM-II, compared with that of PCM-I.

thus reducing the need for further separation processes. The use of cooling crystallisation provides improved control of supersaturation within the system and is the first key step in transfer of the process to continuous crystallisation platforms. Although we have been able to design this templated crystallisation, the mechanism of this templating process is unknown; however it can be suggested that the templating co-former affects the solution-mediated phase transition that normally occurs during the cooling of PCM in the absence of a co-former molecule. This initial transfer into a cooling crystallisation environment provides a key start point for the transfer of this system into continuous platforms at industrial scale.

This work was supported by the EPSRC CMAC under grants $\mathrm{EP} / \mathrm{I033459/1}$ and $\mathrm{EP} / \mathrm{K} 503289 / 1$.

\section{Notes and references}

1 Y. Huang, B. Zhang, Y. Gao, J. Zhang and L. Shi, J. Pharm. Sci., 2014, $103,2330$.

2 J.-X. Song, Y. Yan, J. Yao, J.-M. Chen and T.-B. Lu, Cryst. Growth Des., 2014, 14, 3069.

3 R. Thakuria, A. Delori, W. Jones, M. P. Lipert, L. Roy and N. RodriguezHornedo, Int. J. Pharm., 2013, 453, 101.

4 D. P. Elder, R. Holm and H. L. de Diego, Int. J. Pharm., 2013, 453, 88.

5 N. Shan, M. L. Perry, D. R. Weyna and M. J. Zaworotko, Expert Opin. Drug Metab. Toxicol., 2014, 10, 1255.

6 J. Li, S. A. Bourne and M. R. Caira, Chem. Commun., 2011, 47, 1530. 
7 P. Sanphui, N. R. Goud, U. B. R. Khandavilli, S. Bhanoth and A. Nangia, Chem. Commun., 2011, 47, 5013.

8 M. Karanam, S. Dev and A. R. Choudhury, Cryst. Growth Des., 2012, $12,240$.

9 G. Nichols and C. S. Frampton, J. Pharm. Sci., 1998, 87, 684-693.

10 M.-A. Perrin, M. A. Neumann, H. Elmaleh and L. Zaske, Chem. Commun., 2009, 3181.

11 G. G. Z. Zhang, D. Law, E. A. Schmitt and Y. Qiu, Adv. Drug Delivery Rev., 2004, 56, 371.

12 E. Joiris, P. Di Martino, C. Berneron, A. M. Guyot-Hermann and J. C. Guyot, Pharm. Res., 1998, 15, 1122.

13 H. L. Lee, H. Y. Lin and T. Lee, Org. Process Res. Dev., 2014, 18, 539. 14 C. Sudha and K. Srinivasan, CrystEngComm, 2013, 15, 1914-1921.

15 J. C. Burley, M. J. Duer, R. S. Stein and R. M. Vrcelj, Eur. J. Pharm. Sci., 2007, 31, 271.
16 C. Sudha, R. Nandhini and K. Srinivasan, Cryst. Growth Des., 2014, 14, 705.

17 K. Chadwick, A. Myerson and B. Trout, CrystEngComm, 2011, 13, 6625. 18 L. H. Thomas, C. Wales, L. H. Zhao and C. C. Wilson, Cryst. Growth Des., 2011, 11, 1450.

19 A. Saleemi, I. I. Onyemelukwe and Z. Nagy, Front. Chem. Sci. Eng., 2013, 7, 79.

20 C. Thompson, M. C. Davies, C. J. Roberts, S. J. B. Tendler and M. J. Wilkinson, Int. J. Pharm., 2004, 280, 137.

21 T. McGlone, N. E. B. Briggs, C. A. Clark, C. J. Brown, J. Sefcik and A. J. Florence, Org. Process Res. Dev., 2015, 19, 1186.

22 J. Garside and M. B. Shah, Ind. Eng. Chem. Process Des. Dev., 1980, 19, 509.

23 I.-C. Wang, M.-J. Lee, D.-Y. Seo, H.-E. Lee, Y. Choi, W.-S. Kim, C.-S. Kim, M.-Y. Jeong and G. J. Choi, AAPS PharmSciTech, 2011, 12, 764. 